\title{
A CONTRIBUIÇÃO DA SOCIOLOGIA PARA A ANÁLISE DE POLÍTICAS PÚBLICAS
}

\author{
Soraya Vargas Cortes \\ Luciana Leite Lima
}

Políticas públicas são "o campo do conhecimento que busca, ao mesmo tempo, 'colocar o governo em ação' e analisar essa ação” (Souza, 2006, p. 26). O governo que age não pode ser tratado pelo analista como uma organização monolítica e apartada da sociedade, pois esta não apenas o influencia e o legitima, como também é, em grande parte, modelada e transformada pelas políticas governamentais (Pierson, 1993). A complexidade envolvida nas relações entre Estado e sociedade é uma das razões pelas quais as políticas públicas são intrinsecamente interdisciplinares. Essa afirmação se aplica tanto à disciplina acadêmica que estuda as práticas sociais presentes nos processos de elaboração, implementação e avaliação de políticas, quanto às práticas ou ações de atores e decisores políticos. Além dessa ambiguidade de se referir a abordagens analíticas e a práticas sociais, a análise de políticas públicas está impregnada por uma ambivalência implícita: ela é, ao mesmo tempo, uma disciplina específica, com objeto próprio cuja definição tem motivado intensos debates (Souza, 2006), e um campo claramente interdisciplinar, com fronteiras disciplinares porosas, espe- 
cialmente entre as ciências sociais básicas e aplicadas que oferecem os fundamentos teóricos e metodológicos desse campo de conhecimento.

A natureza interdisciplinar desse campo produziu, em diferentes países, padrões diversos de institucionalização. Nos Estados Unidos, a análise de políticas públicas surgiu nos anos de 1950 e constituiu a ação dos governos como seu objeto primordial de estudos (Souza, 2006). Como área de conhecimento institucionalizou-se como uma disciplina próxima à ciência política. Na Grã-Bretanha, também a partir dos anos de 1950, a administração social organizou-se como uma espécie de arcabouço instrumental prático aplicado à gestão do Estado de bem-estar social. A partir da década de 1970 , as políticas sociais (social policy) institucionalizaram-se como uma disciplina específica, cujo foco analítico é a investigação da produção, desenvolvimento e produção das políticas (Alcock, 2003). Fruto da crítica ao administrativis34 mo ingênuo do passado, essa disciplina instituiu-se como uma área de conhecimento acadêmico com ambições analíticas e com referencial teórico principalmente assentado na sociologia e nas teorias do Estado (Pinker, 1989). Portanto, o campo das políticas públicas não é "essencialmente" mais próximo a uma ou outra área das ciências sociais. Trajetórias históricas particulares, em ambientes acadêmicos e políticos nacionalmente diferentes, conformaram diversas institucionalidades e padrões de proximidade com outras disciplinas acadêmicas.

No Brasil, até o final dos anos de 1990, o campo das políticas públicas era apropriadamente descrito como de institucionalização bastante incipiente, marcado por uma fragmentação organizacional e temática e pela "prevalência de burocracias públicas na produção de análises sobre políticas" (Melo, 1999, p. 66). Passada pouco mais de uma década, essa apreciação não parece mais retratar a realidade da área (Faria, 2011). 
Nos últimos anos, o campo das políticas públicas se expandiu de forma significativa. A mudança foi impulsionada, entre outras razões, pela crescente importância que a questão da promoção do desenvolvimento conjugado a políticas sociais passou a ocupar na agenda governamental (Draibe e Riesco, 2009). Houve também expressivo aumento dos empregos na administração pública ou em organizações não governamentais e privadas ${ }^{1}$, especialmente naquelas envolvidas na provisão de serviços sociais. Em paralelo, observou-se a expansão acelerada da formação graduada e pós-graduada na área de políticas públicas (Faria, 2011).

Aquilo que Faria (2011) denominou como um verdadeiro boom das políticas públicas no Brasil a partir dos anos 2000 , tem se processado com a participação de diversas disciplinas correlatas. A classificação de áreas do conhecimento do Conselho Nacional de Desenvolvimento Científico e Tecnológico $(\mathrm{CNPq})$ considera as políticas públicas como uma subárea da ciência política. De fato, sua institucionalização processa-se predominantemente junto dessa disciplina, haja vista a crescente estruturação da área temática "Estado e políticas públicas" na Associação Brasileira de Ciência Política (ABCP). Porém, o seu caráter interdisciplinar manifesta-se na dispersão dos cursos de políticas e de gestão públicas nas diversas áreas de avaliação da Capes (2011) e nos diferentes departamentos de instituições de ensino superior e de pesquisa envolvidos com a temática. Mais relevante ainda, os objetos de investigação do campo

\footnotetext{
${ }^{1}$ Em 1992, 4,5\% das pessoas ocupadas, com dez anos ou mais de idade, estavam empregadas no setor público, enquanto, em 2007, o percentual subiu para $8,6 \%$ (IBGE, 2008). No entanto, há muito mais pessoas ocupadas em atividades relacionadas à provisão de serviços ou bens públicos, uma vez que grande parte dessa provisão é realizada por organizações da sociedade civil e de mercado. Os postos de trabalho do grupamento "educação, saúde, serviços sociais, administração pública, defesa e seguridade social”, utilizado pelo IBGE (2010), representavam $21,5 \%$ do total de pessoal ocupado, em 2007, no Brasil. O grupamento, que estava entre os que apresentavam os maiores níveis de rendimento, teve um aumento de 2,7\% nos postos de trabalho entre 2005 e 2006.
} 
requerem recursos teóricos e metodológicos variados, procedentes de várias tradições disciplinares. Ao tratar fundamentalmente da ação dos governos, os pesquisadores pressupõem que essa ação - e o que a provoca - transborde os limites estatais ou a esfera da política. Assim, o foco dos estudos recai sobre um dos temas de pesquisa mais caros à sociologia política: as relações entre Estado e sociedade. No entanto, a contribuição da sociologia para o campo das políticas públicas é ainda mais ampla.

Ao prosseguir na reflexão sobre o tema iniciada em outra publicação (Cortes, s.d.), o artigo busca aprofundar a compreensão sobre como a sociologia auxilia a análise de políticas públicas. São vários os caminhos analíticos que poderiam ser seguidos, dada a diversidade de perspectivas teóricas e epistemológicas encontradas na sociologia contemporânea. Optamos por focalizar as relações entre Estado e sociedade, principalmente enfatizando atores, 36 processos e estruturas que se localizam principalmente na dimensão societal desse binômio.

$\mathrm{O}$ artigo está dividido em três seções. A primeira trata da contribuição da disciplina para a compreensão do papel dos grupos sociais. A segunda aborda os imperativos cognitivos e normativos e a influência destes na formação e implementação de políticas públicas. A terceira examina como o debate sociológico sobre estruturas e instituições sociais pode auxiliar na análise de políticas. Embora possam ser separados analiticamente, os três conjuntos de respostas à indagação sobre a contribuição da sociologia para a análise de políticas públicas estão profundamente relacionados, como será visto a seguir.

\section{Os grupos sociais: identidades e atores}

Porque explora as bases sociais de processos políticos e da relação entre Estado e sociedade, a contribuição da sociologia é bastante relevante para a análise de grupos sociais, 
que compõem, ao lado de outros elementos, o polo societal dessa relação. "Grupos sociais" aqui se refere, genericamente, aos atores coletivos formados por secções da sociedade, que são denominados de diferentes maneiras conforme a teoria social empregada.

Uma das preocupações centrais da sociologia, desde os clássicos, foi examinar essas secções para caracterizar a organização estratificada da sociedade. A colaboração da sociologia contemporânea para a análise de políticas públicas, sob esse aspecto, pode ser classificada em duas vertentes: a das identidades sociais e a dos atores. A primeira vertente refere-se aos estudos acerca da constituição de grupos sociais que podem demandar ou ser objeto de políticas públicas. Esses estudos acentuam, em geral, o caráter relacional da construção de identidades sociais. A produção de uma identidade específica está vinculada ao compartilhamento de uma matriz cognitiva e normativa que é fonte de coesão grupal e do estabelecimento de fronteiras com outros grupos identitários (Muller e Surel, 2002). Para existir, uma identidade necessita de outra, que demarca a diferença entre ambas ao explicitar o que a primeira delas não é.

Recentemente, as teorias do reconhecimento e da construção de identidades e alteridades sociais têm colaborado para o entendimento desse fenômeno. O termo reconhecimento se refere ao processo por meio do qual, a partir das relações intersubjetivas em que um sujeito se impõe e se contrapõe a outro, identidades individuais e coletivas são afirmadas (Honneth, 2003; Taylor, 1994). O modelo da luta pelo reconhecimento é a ação coletiva na qual o desrespeito, o não reconhecimento e a dominação cultural (Fraser, 2001) de uma determinada forma de ser no mundo ensejam "um conflito cujo principal resultado é a 'evolução moral' da sociedade” (Figueiredo, 2008, p. 17). Essa vertente de análise subsidia o estudo sobre a construção de 
novas identidades sociais. Intensas migrações, transformações econômicas, culturais e no mercado de trabalho, ao propiciarem a constituição de novos atores coletivos, acirraram as lutas pelo reconhecimento. Os novos atores têm sido objetos de estudo da sociologia, que examina os ideais deles, os discursos produzidos por e sobre eles, a ação política e a própria construção desses grupos a partir da ação estatal que os reconhece, hierarquiza e os institui como beneficiários de políticas e como atores societais. Os estudos sobre políticas públicas classificados como "construcionistas sociais" são, talvez, os principais tributários desse tipo de contribuição (Ingram et al. 2007).

No que tange à segunda vertente analítica, a dos atores, a sociologia política tem empregado com frequência o conceito de atores estatais e societais - da sociedade civil e de mercado - para classificar grupos sociais que agem na esfera política. A origem direta desse uso está na interface entre os 38 debates sobre sociedade civil e a teoria democrática (Cohen e Arato, 1992), mas a fonte teórica pode ser encontrada nos estudos de Gramsci (2004), Touraine (1981) e Melucci (1985) sobre a sociedade civil e, principalmente, na concepção deliberativa da esfera pública de Habermas (1989) e seus seguidores (Cohen, 2003). A partir da distinção dos habermasianos entre sistema e mundo da vida e as implicações institucionais desta (Cohen e Arato 1992), argumenta-se "[...] que as instituições e os atores pertencentes aos dois subsistemas coordenados por via do poder e do dinheiro - Estado e economia capitalista de mercado - estão sujeitos a uma série de restrições que não afetam os atores da sociedade civil" (Cohen, 2003, p. 427).

O conceito de atores estatais abarca tanto indivíduos que ocupam cargos de direção em órgãos do Executivo ou em organizações governamentais como aqueles que têm algum vínculo com órgãos do Legislativo ou Judiciário. $\mathrm{O}$ conceito de atores societais é amplo demais para expressar 
diferenças essenciais entre dois tipos de atores: os sociais e os de mercado. Enquanto os primeiros estão associados ao conceito de sociedade civil, os segundos estão relacionados com a noção de economia de mercado. A sociedade civil e seus atores seriam diferentes do Estado e do mercado e também de seus respectivos atores. Segundo Cohen (2003), os atores estatais e de mercado seriam compelidos a agir em ambientes regidos pelo poder e pelo dinheiro, enquanto o mesmo não aconteceria com os atores sociais. Estes não visam tomar o poder do Estado ou organizar a produção, mas sim "exercer influência por meio da participação em associações e movimentos democráticos" (Cohen, 2003, p. 427). Atores de mercado buscam controlar e administrar a produção, maximizar seus lucros no ambiente de trocas mercantis. Os decisores econômicos, por mais que discutam problemas como os impactos sociais ou ambientais de ações empresariais e decisões estatais, não podem se furtar aos imperativos da produtividade e do lucro; suas ações políticas seriam guiadas por tais imperativos.

Nas últimas duas décadas do século XX, a sociologia privilegiou o estudo de redes sociais (Castells, 1999; McAdam, 2003; Melucci, 2001; Scherer-Warren, 1993) cujas fronteiras localizaram-se, sobretudo, no âmbito societal. Mas, independentemente dos limites societais ou estatais das redes analisadas, as referências mais frequentes do conceito podem ser encontradas na obra de Elias (1994, 2000), que trata do "social" como conjunto de relações que estão "em processo, isto é: elas se fazem e desfazem, se constroem, se destroem, se reconstroem" (Waizbort, 1999, p. 92). A sociedade é percebida como uma rede de indivíduos e grupos em constante relação, compreensível em termos de relações recíprocas (Elias, 1994).

A noção de "rede" se tornou paradigmática tanto na sociologia quanto na análise de políticas públicas. Nos anos 
1990, o sociólogo Emirbayer (1997) lançou seu manifesto por uma sociologia relacional, enquanto a analista de políticas públicas Börzel afirmou que o termo redes se tornara "o novo paradigma para a arquitetura da complexidade" (1998, p. 1). Na obra de ambos, a ideia central é a de que existem atores cuja natureza não permite que sua posição seja determinada em relação ao Estado, ao mercado ou à sociedade civil. Esse seria o caso das comunidades de políticas (policy communities) que agem em contextos de redes de políticas públicas (policy networks). Essas comunidades são atores em rede que não podem ser situadas como societais ou estatais, pois seus integrantes estão situados no Estado e na sociedade. Elas se constituem a partir das relações de atores individuais e coletivos no interior de redes existentes em áreas específicas de políticas públicas. Como afirmam True et al., essas comunidades podem ser denominadas "como triângulos de ferro, nichos temáticos, subsistemas políticos, 40 redes temáticas”, mas

[...] qualquer que seja a denominação adotada, ela se refere a uma comunidade de especialistas operando fora do processo político visível, em contextos nos quais a maior parte das questões de cada política setorial específica é tratada no interior de uma comunidade de experts (2007, p. 157-8).

Redes sociais e normas sociais formam-se mutuamente. Categorias cognitivas e normativas, convenções, regras, expectativas e lógicas que dão às normas sociais sua força também são condição para a formação de redes estruturadas que funcionam como os "esqueletos" de campos ou de sistemas de políticas (policies). Enquanto redes geram hierarquias que colaboram na definição e na eficácia das regras, normas sociais dão forma às estruturas e condicionam comportamentos individuais e grupais. 


\section{Os imperativos cognitivos e normativos}

Também se refere ao polo societal das relações entre Estado e sociedade outra relevante contribuição teórica da sociologia para a análise de políticas públicas: os imperativos cognitivos e normativos, que designam ideias, teorias, modelos conceituais, normas, visões de mundo, quadros de referência, crenças e princípios. Os imperativos cognitivos derivam de paradigmas que oferecem "descrições e análises que especificam relações de causa e efeito consideradas como inquestionáveis". Os quadros de referência normativos, e as ideias normativas, "consistem em pressupostos inquestionáveis [...] sobre valores, atitudes, identidades e expectativas coletivamente compartilhadas" (Campbell, 2002, p. 22-3).

Na literatura das políticas públicas, as categorias normativas são geralmente tratadas como instituições não formalizadas, informais regras do jogo que constituem e regulam o comportamento social (DiMaggio, 1994; Ostrom, 2007). Tema clássico da sociologia, central na obra de Durkheim e de Weber, as normas sociais foram definidas de maneiras diversas conforme as abordagens teórico-epistemológicas dos analistas. Para a teoria da escolha racional, as normas estabelecem restrições, limites ou sanções aos possíveis cursos de ação de atores que buscam a realização de seus interesses, de modo que comportamentos não normativos envolvem altos custos para aqueles que, por ventura, os escolherem. Para o interacionismo simbólico, as normas sociais oferecem orientações sobre como pensar e agir a atores motivados pelos significados subjetivos que atribuem às próprias ações e ao mundo que os cerca. Tais significados são derivados das interações sociais e das interpretações que constroem inclusive sobre si (identidade ou self). Existem divergências sobre que grupos são beneficiados pelas normas; se estas são regras, orientações ou regularidades empíricas; se envolvem necessariamente imperativos morais (Feld, 2002; Wilson, 1993). No entanto, independentemente 
da perspectiva teórica adotada, há consenso entre os sociólogos de que as normas sociais, principal fonte de ordem social e previsibilidade, são caracterizadas pela regularidade de comportamento e por sanções àqueles que não as seguem (Feld, 2002).

Os estudiosos têm prestado pouca atenção ao efeito das categorias cognitivas, das normas sociais - como as derivadas de diversas formas de crenças -, da propensão à inovação e das tradições políticas sobre as políticas públicas (Campbell, 2002; Faria, 2003; Miller e Banaszak-Holl, 2005) ${ }^{2}$. Expressão disso é que, dos três tipos de abordagens neoinstitucionalistas, que têm poderosa influência para a análise de políticas (Hall e Taylor, 1996; Peters et al., 2005), as vertentes histórica e da escolha racional, que são as mais utilizadas pelos estudiosos, são também aquelas que menos enfatizam os imperativos cognitivos e normativos na explicação dos processos políticos.

42 Com a expectativa de que as instituições têm forte efeito sobre o comportamento individual e dos grupos, os institucionalistas históricos focalizam o papel que estas cumprem sobre o desenvolvimento de determinadas condutas pessoais e coletivas, argumentando que instituições são tanto as estruturas formais quanto as regras informais que as guiam (Miller e Banaszak-Holl, 2005). Para eles, muitas estruturas e resultados de políticas não são planejadas por atores individuais ou coletivos, mas sim escolhas realizadas sob o constrangimento, por vezes abrupto, de instituições (Scott, 1992). Se as normas sociais informais são consideradas instituições, como frequentemente o são nos estudos dessa corrente, em certa medida, categorias cognitivas são levadas em conta na explicação dos fenômenos sociais e políticos (Hall e Taylor, 1998). Entretanto, as nor-

\footnotetext{
${ }^{2}$ A exceção são as investigações sobre cultura política, que "pode ser definida como as diferenças históricas e entre os países no que tange às atitudes, hábitos e sensibilidades a determinados tipos de questões" (Miller e Banaszak-Holl, 2005, p. 192).
} 
mas parecem agir, em termos relativos, de forma mecânica sobre indivíduos e grupos, uma vez que a ênfase é depositada nos constrangimentos à capacidade que eles têm de refletir e de fazer escolhas.

Para explicar a existência das funções desempenhadas pelas instituições, os neoinstitucionalistas da escolha racional tomam "como referência que os valores dos atores afetados" podem definir as funções das instituições (Miller e Banaszak-Holl, 2005, p. 194). Havendo oportunidade e poder para tanto, atores fazem escolhas ao constituírem instituições com o objetivo racional de institucionalizar seus valores privados e, conforme suas convicções, obterem vantagens. Regras institucionais alteram os incentivos e o comportamento subsequente de atores racionais. De modo diverso dos neoinstitucionalistas históricos, aqui é acentuada a capacidade de escolha dos atores. Constrangidos por instituições, indivíduos e grupos são vistos como capazes de fazer escolhas racionalmente autointeressadas, mesmo que essa racionalidade seja admitida como limitada (Ostrom, 2007; Simon e Marsh, 1967). Porém, a dimensão cognitiva se restringe à motivação autointeressada da ação de indivíduos e grupos. Os valores que estes possuem, que, por sua vez, estão relacionados a seus interesses materiais e imateriais, definem o modo como indivíduos e grupos agem no processo de construção institucional e de defesa do próprio autointeresse.

Essa abordagem é a que mais se contrapõe às tradições sociológicas durkheimianas e estruturalistas, que veem pouco espaço para a ação racional utilitária dos indivíduos, além da resistência aos papéis que a posição destes nas estruturas sociais lhes atribui. Mesmo o marxismo, que concebia o protagonismo do proletariado e a possibilidade de indivíduos alcançarem a consciência de classe, desenvolveu o conceito de alienação para mostrar como a macroestrutura capitalista dificultava a concretização dessa possibili- 
dade (Collins, 1994). A exceção era a vertente weberiana, que atribuía às ideias papel central nas mudanças sociais e que considerava que o fim máximo da sociologia era o de compreender as motivações dos indivíduos para a ação. Mas, para Weber, a ação racional "instrumental" era apenas um dos tipos possíveis de racionalidade para ação.

Dentre os principais autores na sociologia contemporânea, talvez seja Giddens o que mais tenha se aproximado da visão do neoinstitucionalismo da escolha racional ao respeito do modo como agem os indivíduos frente às instituições. Giddens (1989) construiu sua teoria da estruturação e suas concepções acerca da reflexividade dos agentes sobre os fundamentos teóricos das propostas da "terceira via". Para ele, os indivíduos podem intencionalmente fazer escolhas. Os seres humanos não estão meramente seguindo "roteiros" ou regras institucionais ou estruturais, mas são agentes reflexivos (Giddens, 1989). Os indivíduos são responsáveis

44 por suas próprias ações, embora não possam ser responsabilizados pelas circunstâncias em que fazem escolhas. Entretanto, quaisquer que sejam essas circunstâncias, sempre há alternativas para eles optarem. A convergência com a corrente racional/utilitária está exatamente na concepção de que os beneficiários de políticas de bem-estar são consumidores ou usuários ativos, capazes de refletirem e de fazerem escolhas racionais de acordo com os próprios interesses.

Vários estudos têm criticado a obra de Giddens no que tange à ênfase exagerada no conhecimento dos atores sobre as instituições, ao viés voluntarista e à subestimação do funcionamento subjacente das instituições (Archer, 1990; Hoggett, 2001; McAnulla, 2002; Williams, 1999). Independentemente das críticas que suscitou, o trabalho de Giddens inspirou análises e propostas na área de políticas públicas que focalizam a reflexividade humana, em contraste com aquelas que enfatizam estruturas e instituições como explicativas da ação dos indivíduos e grupos. As 
concepções dele ofereceram as bases teóricas e orientaram a formulação e a implementação das políticas sociais pelos governos trabalhistas, na Grã-Bretanha, e pelos democratas, nos EUA, nos anos de 1990.

A terceira tradição neoinstitucionalista, a sociológica, é a menos frequente nas análises de políticas públicas. Para os estudiosos dessa corrente, atores buscam obter legitimidade ante "às pressões institucionais para que se submetam às regras culturais, às normas e às expectativas, independentemente da eficiência das práticas que adotem" (Miller e Banaszak-Holl, 2005, p. 195). O processo de "isomorfismo institucional", identificado pelos institucionalistas sociológicos, expressa essa concepção (DiMaggio e Powell, 1983). As organizações, inclusive as estatais, vão se tornando similares porque adotam elementos e práticas legitimadas socialmente que emergem e são definidas no ambiente institucional mais amplo. Para eles, o ambiente institucional promove homogeneidade porque consiste em um paradigma cognitivo e um quadro de referência normativo que limita o espectro de alternativas que os decisores tendem a perceber como apropriadas. As organizações adotam certas características e desenvolvem determinadas políticas porque querem ser consideradas legítimas no ambiente societal em que se inserem.

Para o neoinstitucionalismo sociológico, um conceito central é o de "setor societal", que inclui: (1) o conjunto de organizações que operam em um domínio singular, identificado pela similaridade dos serviços, produtos ou funções e (2) outras organizações que influenciam o desempenho de organizações focais tais como provedores-chave, consumidores, agências regulatórias, fontes de financiamento e competidores (Miller e Banaszak-Holl, 2005). Sua importância na pesquisa sobre políticas públicas está relacionada à concepção de que as organizações políticas derivam seus modelos de funcionamento dos imperativos culturais prove- 
nientes do ambiente societal. Ao invés de priorizar o estudo das agências governamentais, do legislativo ou dos grupos de interesse em determinado nível de governo na construção de explicações sobre as políticas públicas, os institucionalistas sociológicos concentram-se no exame das redes de políticas públicas, que incluem atores de diversos níveis de governo, de mercado e da sociedade civil. Nesse contexto, focalizam também os atores que se organizam em redes, como as comunidades de políticas.

A influência da sociologia, através da atribuição de capacidade explicativa de elementos - atores, imperativos cognitivos e normativos - encontrados no setor societal, também ocorre entre os analistas que examinam como certos "problemas" passam a fazer parte da agenda governamental (Kingdon, 1995; Muller e Surel, 2002; Sabatier e Jenkins-Smith, 1993; Sabatier e Weible, 2007). Mesmo admitindo que os constrangimentos institucionais e even46 tos macroestruturais limitem as possibilidades de problemas se tornarem objeto de política, esses estudiosos examinam os processos cognitivos e as dimensões normativas envolvidas na formação da agenda governamental. Isso porque consideram que "problemas" não são dados, mas sim construídos em um processo através do qual as pessoas os definem como tal (Kingdon, 1995). Atores da sociedade constroem determinadas problemáticas, formulam certas explicações e soluções para elas e apresentam-nas à esfera política com o objetivo de inserir esses problemas, e também as explicações e propostas de solução, na agenda governamental (Sabatier e Jenkins-Smith, 1993). Tanto a construção dos problemas na esfera societal quanto a seleção daqueles que integrarão a agenda dos governos dependem dos valores, crenças, posições e interesses dos atores societais e governamentais (Sabatier e Weible, 2007). Assim, os próprios atores societais podem construir e resolver problemas, independentemente da ação dos 
governos (Muller e Surel, 2002). Porém, uma vez na agenda, os governantes passam a formular políticas para lidar com esses problemas, políticas estas que, ao serem implementadas, constroem ou transformam os espaços de sentido já existentes e, no interior destes, os grupos sociais definem e redefinem os problemas. As próprias políticas colaboram, portanto, para a formação de um sistema de ação, um espaço de trocas constituído por relações de poder, no qual ocorre a interação entre múltiplos atores, situados em diferentes organizações.

Desse modo, as políticas públicas são entendidas como construções de matrizes cognitivas que determinam, ao mesmo tempo, as medidas (ações, atividades, programas, por exemplo) passíveis de serem adotadas - porque legítimas - e os espaços de sentido particular, no interior das quais os atores interagem (Muller e Surel, 2002). Por um lado, elas mesmas são responsáveis pela construção de um quadro normativo de ação que conforma a possibilidades de imagens da realidade, de ação e de justificativa para a ação dos vários atores envolvidos. Por outro, as políticas públicas particulares tendem a ser locais: constructos políticos autônomos que, em seu nível próprio de atuação, regulam as relações de conflito entre os grupos sociais ao assegurar as possibilidades de articulação e de harmonização dos interesses envolvidos.

No entanto, as abordagens examinadas nesta seção, ao tratarem dos imperativos cognitivos e normativos na análise de políticas públicas, reconhecem a importância das estruturas sociais e das instituições sociais e políticas. Atores societais, estatais ou organizados em redes têm suas possibilidades de reflexão e de ação limitadas por instituições e pela estrutura social que estratifica o acesso a recursos de poder. Os imperativos normativos e cognitivos tornam-se, ao longo do tempo, instituições não formalizadas e de difícil transformação. Por essas razões, e devido ao lugar central 
que essas instituições ocupam nas explicações sociológicas, a seguir, é examinada a contribuição da sociologia para a compreensão do papel dessas estruturas e instituições no campo das políticas públicas.

\section{Estrutura social e instituições}

Estudos sobre estratificação, estrutura social e desigualdade social e as relações destas últimas com as instituições políticas são objeto de análise da sociologia desde os clássicos (Durkheim, 1999; Marx, 1964; Weber, 1977). Um dos resultados dessas investigações foi a constatação de que existem oportunidades desiguais de acesso a bens e serviços - sejam individuais ou coletivos - e que disso decorrem possibilidades diferenciadas de exercício de influência sobre processos políticos. Se, por um lado, o marxismo atribui ao sistema econômico capitalista a explicação fundamental para tais desigualdades, teorias socio48 lógicas inspiradas na obra de Durkheim e Weber as associam, respectivamente, a processos de diferenciação social que asseguram a integração funcional das sociedade e a fatores econômicos e extraeconômicos como status social e afiliação político partidária. No entanto, mesmo as vertentes teóricas neomarxistas incorporam "recursos de poder", derivados da esfera política, na explicação de alterações na estratificação social nas sociedades contemporâneas (Korpi, 2000; Offe, 1989; Touraine, 1981). Isto porque consideram que a ação política amplia os recursos organizativos dos trabalhadores ou dos movimentos sociais e assim, por meio da ação coletiva, os integrantes de estratos sociais inferiores podem produzir políticas que favoreçam a redução de desigualdades sociais.

Para explicar a produção, a reprodução e a mudança em sistemas sociais estratificados, sociólogos contemporâneos como Bourdieu (1989), Giddens (1989) e Luhmann (1991) analisam, com lentes teóricas diversas, como os diversos 
"campos", sistemas e subsistemas sociais se instituem como estruturas sociais assimétricas baseadas em critérios especializados, pertinentes ao conteúdo em questão (setor educacional, área hospitalar, por exemplo), e em regras de distinção entre os que ocupam posições nessas estruturas. Os critérios de diferenciação e de estabelecimento de hierarquias sociais são considerados, em geral, como fundamentados na posse desigual de recursos e na posição social que os indivíduos e grupos ocupam nas estruturas sociais. Em geral, aqueles que estão no topo das hierarquias sociais de um dado campo, sistema ou subsistema têm mais facilidade de ocupar posições superiores em hierarquias de outros sistemas por meio de mecanismos de conversão de estoques de recursos acumulados (Peillon, 1999). Esses indivíduos e grupos podem mais facilmente expressar suas preferências, exercer influência sobre os decisores políticos em macrossistemas ou subsistemas políticos, participar da formação de agendas governamentais e exercer certo controle sobre o modo como são implementadas as políticas públicas.

Fundamentais para a análise, formulação e implementação de políticas públicas, as instituições podem tanto designar organizações responsáveis por inculcar normas sociais em indivíduos e grupos quanto normas sociais em si mesmas, "regras", "prescrições compartilhadas (deve, não deve, pode ou não pode) que são mutuamente entendidas e previsivelmente implementadas em situações particulares por agentes responsáveis por monitorar a conduta e por impor sanções" (Ostrom, 2007, p. 23). O estudo de instituições enquanto organizações, mas também enquanto normas sociais, tem como referência importante na sociologia contemporânea as obras de Goffman $(1959,1961)$ e de Foucault $(1979,1987)$.

\footnotetext{
${ }^{3}$ Um espaço cujas características são definidas pela configuração das inter-relações entre atores individuais e coletivos, interessados e atuantes nesse campo, e pelas lutas travadas por esses atores ao disputarem por posições superiores na configuração (Owen-Smith e Powell, 2008; Harker et al., 1990).
} 
Goffman desenvolveu a teoria do ritual de Durkheim ao aplicá-la a todos os aspectos dos encontros sociais. Empregando a analogia com o teatro, o autor afirmava que os rituais não apenas criam imagens do self, negociam laços sociais e controlam os outros, mas também requerem recursos materiais e culturais (Collins, 1994). Ao mesmo tempo que mantêm a sociedade coesa, a estratificam. Ao analisar hospícios, prisões, campos de concentração, monastérios, orfanatos e organizações militares como instituições totais, o foco de Goffman recaiu sobre os rituais: os que demarcam a rígida separação hierárquica entre dois grupos de "internos", os que trabalham na instituição e os que estão a ela confinados; os que asseguram que os confinados se livrem das identidades que tinham antes de entrarem na instituição e assumam novos papéis. Segundo Goffman, são necessidades estruturais que comandam o processo de racionalização que leva à destruição do antigo e à criação de um novo self nos indivíduos 50 (Weinstein, 1982). Estudos inspirados na teoria de Goffman têm examinado também hospitais não psiquiátricos, asilos para idosos, entre outros tipos de organizações (Holm e Smidt, 1997; Hook et al., 1982).

A extensa obra de Foucault pode ser dividida em duas grandes fases: arqueologia do discurso e genealogia do poder/saber. Para o campo das políticas públicas, a segunda fase é a mais relevante, pois através dos conceitos de governamentalidade ${ }^{4}$ e biopoder ${ }^{5}$ focaliza o poder que

\footnotetext{
4 "Foucault define governamentalidade através da conjugação de três elementos. Primeiro, o conjunto formado por instituições, práticas, análises, conhecimentos, cálculos e táticas, que, por meio de mecanismos de segurança e da economia política, permite o exercício de um complexo tipo de poder sobre a população. $O$ segundo elemento consiste na tendência para a proeminência do poder governamental em relação a outros tipos de poder, nomeadamente o poder soberano. Por fim, a governamentalização do estado administrativo, em combinação com os efeitos dessa governamentalização sobre as interações entre os indivíduos, o estado e a sociedade" (Militão e Pinto, 2008, p. 5).

${ }^{5} \mathrm{O}$ biopoder trata do conjunto de processos de natalidade, longevidade e mortalidade, seja comparando a proporção dos nascimentos e dos óbitos, seja verificando
} 
age de maneira explícita sobre os corpos dos indivíduos, disciplinando práticas de ser e maneiras de compreender os outros (Chaput, 2009). Segundo o autor, o poder disciplinar - por meio de instituições modernas como o exército, a fábrica, o hospital, a medicina, a escola, o presídio - e do biopoder - ativando mecanismos regulamentadores estatais - desenvolvem políticas de coerção sobre o corpo, que manipulam elementos, gestos e comportamentos deste. Porém o mais relevante não é a coação, mas o caráter produtivo do poder que constrói, destrói e reconstrói, transforma, acrescenta, diminui, modifica - a cada momento e em cada lugar - a si mesmo e tudo com que se relacione (Pogrebinschi, 2004). Os estudos de Foucault tiveram grande influência em diversos ramos temáticos da sociologia (violência, saúde, educação, cultura, entre tantos outros), os quais também são temas setoriais do campo das políticas públicas.

Embora as matrizes teóricas dos dois autores sejam contrastantes - Goffman, durkheimiana, e Foulcault, pós-estruturalista -, eles compartilham a preocupação em construir explicações para o modo como os indivíduos são e agem nas sociedades contemporâneas, localizando-as em normas sociais. Instituições sociais, entendidas como regras e também como organizações, compelem os indivíduos a assumirem papéis sociais a elas adequados e a sociedade a se manter integrada (Goffman, 1959). Por meio do poder disciplinar e do biopoder, as instituições constrangem as pessoas a serem normais e a sociedade a aumentar a produtividade das fábricas, da criação do

a taxa de fecundidade de uma população. "Não intervém no indivíduo, no seu corpo, como faz o poder disciplinar; ao contrário, intervém exatamente naqueles fenômenos coletivos que podem atingir a população e afetá-la - disso decorre que precisa estar constantemente medindo, prevendo, calculando tais fenômenos e, para isso, o biopoder cria alguns mecanismos reguladores que o permitam realizar tais tarefas como, por exemplo, aumentar a natalidade e a longevidade, reduzir a mortalidade e assim por diante" (Pogrebinschi, 2004, p. 176). 
saber, de serviços de saúde (Foucault, 1987). Não obstante postularem tais condicionamentos sociais, os dois autores reconhecem a importância do indivíduo em si mesmo - o self-em particular, na sociedade moderna. Para Goffman, o self, "longe de constituir uma dimensão psicológica localizada e fixada no interior do indivíduo, é o resultado de um processo social" (Martins, 2008, p. 140). Porém, os indivíduos que assumem papéis e posições em hierarquias sociais nas diferentes interações em que se envolvem, procuram afirmar e preservar a própria autonomia e dignidade pessoal diante do poder de forças estruturais, mediante uma variedade de pequenas estratégias de resistência, mesmo que não consigam obter um autodomínio absoluto de seus atos (Martins, 2008; Collins, 1994). Para Foucault (1996), o self estrutural e historicamente produzido busca transformar-se em "outro" nos processos de autoconhecimento nos quais redefine seus princípios éticos. Para isso 52 são acionadas "técnicas de si” por meio das quais indivíduos efetuam operações sobre seus corpos, seus pensamentos, suas condutas e seus modos de ser para "transformar-se a fim de atender um certo estado de felicidade, de pureza, de sabedoria, de perfeição ou de imortalidade" (Foucault, 1996, p. 48). A concepção de indivíduo dos autores é, portanto, bastante complexa e se distancia muito do modelo utilitarista de indivíduos e grupos agindo porque motivados pelo autointeresse.

Dada a perspectiva microssociológica de boa parte desses estudos - mesmo se a dimensão microssocial é vista como reflexo de macroestruturas -, os instrumentos teóricos por eles desenvolvidos são particularmente úteis para o exame de processos de implementação de políticas públicas. Podem ser utilizados para analisar as relações entre os responsáveis diretos pela oferta de bens e serviços públicos e beneficiários ou ainda para o estudo de burocracias governamentais ou institucionais. 
Perspectivas teóricas muito influentes na análise de políticas públicas que atribuem causalidade às macroestruturas, concebem as regras, as convenções e as expectativas de como agir como instituições. Elas definem as ações consideradas apropriadas e as posições de indivíduos e grupos em estruturas sociais hierarquizadas, tratadas como sistemas macropolíticos, campos, sistemas ou subsistemas setoriais (Howlett e Ramesh, 1998; McCool, 1998; Orr, 2006; Sabatier, 1988; Worsham, 1998).

Os modelos analíticos neoinstitucionalistas são provavelmente a referência teórica mais importante para o estudo de políticas públicas na atualidade. Eles visam entender o papel da arquitetura institucional - que estrutura as interações e as transações que acontecem na arena política - na determinação de resultados sociais e políticos. O pressuposto central é o de que as regras institucionais, os procedimentos e as convenções moldam as preferências individuais e estimulam ou limitam as opções de comportamento de indivíduos e organizações por meio de certos mecanismos de incentivo ou de sanção (Hall e Taylor, 1996; Immergut, 1998; Ostrom, 2007; Scharpf, 1997). A predominância dessa abordagem na análise de políticas públicas colaborou para a construção de uma agenda internacional de pesquisas que investigam como os arranjos institucionais colaboram para a produção de resultados que não coincidem com aqueles oriundos da agregação das preferências dos atores individuais ou coletivos situados no topo das hierarquias sociais.

Entretanto, sob essa denominação, estão abrigadas perspectivas com diferentes origens teóricas e visões acerca das relações entre estrutura e agência e, sobretudo, acerca do papel dos imperativos culturais (cognitivos e normativos) na construção de políticas públicas (Hall e Taylor, 1996). O neoinstitucionalismo da escolha racional e a teoria da escolha pública procedem da tradição racional/utilitária 
da sociologia e, mais remotamente, das origens da economia como disciplina acadêmico-científica (Collins, 1994). O neoinstitucionalismo histórico e o sociológico têm raízes teóricas nas tradições sociológicas do conflito - baseadas nos estudos seminais de Marx e de Weber - e, no caso do segundo, também na sociologia durkheimiana.

De modo progressivo, essas e outras vertentes neoinstitucionalistas (Hay, 1996, 2002; Jessop, 1990, 2003) não apenas reconhecem a importância dos instrumentos analíticos umas das outras como os utilizam em suas próprias investigações (Hall e Taylor, 1998). Porém, elas o fazem sem abrir mão de seus modelos explicativos fundamentais ou de suas ontologias sobre estrutura e agência. Expressão disso foi o debate entre Hall e Taylor (1998) e Hay e Wincott (1998) sobre as ontologias sociais e as concepções a respeito das relações entre agência e estrutura nas abordagens neoinstitucionalistas da escolha racional, sociológica e histórica. 54 Não há dúvida entre os autores de que a abordagem do institucionalismo da escolha racional sobre a agência é baseada na ideia do calculus dos agentes sobre como agir diante de uma dada estrutura institucional, considerando a sua posição e a de outros agentes na estrutura social. Concordam ainda que o institucionalismo sociológico fundamenta-se na cultura, ao salientar o papel de imperativos cognitivos e normativos que se originam fora das fronteiras estatais que podem favorecer ou impedir que os agentes adotem políticas (Miller e Banaszak-Holl, 2005). A divergência recai sobre a possibilidade de conjugar essas duas ontologias no institucionalismo histórico. Para Hall e Taylor (1998), assim como para este artigo, essas ontologias não são incompatíveis. A primazia de uma abordagem não impede o reconhecimento da importância e a utilização de instrumentos analíticos da outra. Para os autores não apenas o institucionalismo histórico utiliza formulações concebidas pelo institucionalismo da escolha racional e sociológico, como há um cres- 
cente reconhecimento entre os institucionalistas da escolha racional de que os atores, as instituições com as quais eles operam e o senso comum que informa a ação são culturalmente construídos (Hall e Taylor, 1998).

Neste artigo foram apresentadas três respostas à indagação sobre a contribuição da sociologia para a análise de políticas públicas. A primeira delas destacou a importância dos recursos teóricos que a disciplina oferece ao se debruçar sobre temas dos grupos sociais. A sociologia tem crescentemente examinado os grupos identitários e processos de reconhecimento que se referem aos beneficiários de políticas e aqueles que as demandam; tem também tratado dos atores societais e estatais que agem na formulação e implementação de políticas. Porém, dada a complexificação dos Estados e das sociedades contemporâneas, a sociologia política tem examinado ainda a influência sobre os processos políticos e sobre as decisões governamentais de atores em rede que atravessam as fronteiras entre Estado e sociedade: as comunidades de política, as coalizões de defesa, as comunidades epistêmicas.

A segunda resposta focalizou a importância dos imperativos cognitivos e normativos nos processos políticos que produzem as políticas públicas. Reconhecendo a importância das abordagens neoinstitucionalistas na área, observou-se que a maior parte dos estudos até recentemente não enfatizava a capacidade explicativa desses imperativos. Porém, especialmente o neoinstitucionalismo sociológico, mas também as teorias da formação da agenda, tem chamado atenção para as dimensões que legitimam socialmente determinadas formas de conceber e explicar problemas e de considerar moralmente aceitáveis certas ações e políticas. 
A terceira resposta se referiu aos tipos de explicação, muito frequentes na área de políticas públicas, que ressaltam a importância das estruturas sociais e das instituições na construção e desenvolvimento de políticas. A contribuição da sociologia se expressa no auxílio que oferece para o entendimento de padrões estruturados de iniquidade social e política. Recursos teóricos microssociológicos colaboram também para a compreensão das "instituições" concebidas como organizações socialmente estruturadas que produzem e reproduzem sistemas sociais particulares fortemente hierarquizados. Interessante observar que, mesmo que a ênfase permaneça divergente, o neoinstitucionalismo histórico e o da escolha racional têm progressivamente reconhecido que o os imperativos culturais devem ser incorporados às suas análises.

As tradições sociológicas do conflito - marxistas, weberianas, feministas e pós-colonialistas - são agudas ao analisar 56 as diversas dimensões e explicações da produção e reprodução de desigualdades. A tradição durkheimiana, por exemplo, que enfatiza as condições estruturais, as normas culturais e sociais e a produção de solidariedade, auxilia principalmente no entendimento de como os sistemas sociais se desenvolvem e se reproduzem. Essas tradições sociológicas, enfim, podem auxiliar no desenho de políticas que levem em conta os padrões estruturais de iniquidade social e política, assim como os imperativos culturais que podem tanto favorecer como impedir a viabilidade de políticas públicas. Estudos inspirados nas diversas tradições sociológicas têm abordado de modo progressivo temas do campo das políticas públicas. Todavia, a utilização desse conhecimento dependerá da avaliação dos analistas sobre a relevância deste para a investigação dos objetos de pesquisa específicos do campo das políticas públicas.

Espera-se que este artigo colabore para o debate ainda incipiente no Brasil sobre as relações entre sociologia e polí- 
ticas públicas, uma vez que, como foi demonstrado, aquela é provavelmente uma das principais fontes teóricas para a construção de modelos analíticos desta última.

\section{Soraya Vargas Cortes}

é professora associada do Programa de Pós-Graduação e do Departamento de Sociologia da UFRGS.

\section{Luciana Leite Lima}

é professora adjunta do Departamento de Sociologia da UFRGS.

\section{Referências bibliográficas}

ALCOCK, P. 2003. "The subject of social policy". In: ALCOCK, P. et al. (orgs.). The student's companion to social policy. Malden, MA: Blackwell, pp.1-10.

ARCHER, M. 1990. "Human agency and social structure: a critique of Giddens”. In: CLARK, J. et al. (orgs.). Anthony Giddens: consensus and controversy. London/ New York: Falmer, pp.73-84.

BÖRZEL, T. A. 1998. "Organizing babylon: on the different conceptions of policy networks”. Public Administration, v.76, n.2, pp.253-73.

BOURDIEU, P. 1989. O poder simbólico. Lisboa/ Rio de Janeiro: Difel; Bertrand.

CAMPBELL, J. L. 2002. "Ideas, politics, and public policy". Annual Review of Sociology, v.28, pp.21-38.

CAPES. 2011. "Planilhas comparativas da avaliação trienal 2010". Disponível em http:/ / www.capes.gov.br/component/content/article/44-avaliacao/4355-planilhas-comparativas-da-avaliacao-trienal-2010. Acesso em 5/10/2011.

CASTELLS, M. 1999. Sociedade em rede. Rio de Janeiro: Paz e Terra.

CHAPUT, C. 2009. "Regimes of truth, disciplined bodies, secured populations: an overview of Michel Foucault". Science Fiction Film and television, v.2, n.1, pp.91-104.

COHEN, J. L. 2003. "Sociedade civil e globalização: repensando categorias". Dados, v.46, n.3, pp.419-59. ; ARATO, A. 1992. Civil society and political theory. Cambridge, MA: MIT Press.

COLLINS, R. 1994. Four sociological traditions. New York: OUP.

CORTES, S. M. V. (s.d.). "Sociologia e política". In: MARQUES, E.; FARIA, C. A. (orgs.). A política pública como campo multidisciplinar. [no prelo]. 
DiMAGGIO, P. 1994. "Culture and economy”. In: SMELER, N.; SWEEDBERG, R. (orgs.). Handbook of economic sociology. Princeton, NJ/ New York: PUP; Russell Sage Foundation, pp.27-57

DiMAGGIO, P.; POWELL, W. W. 1983. "The iron cage revisited: institutional isomorphism and collective rationality in organizational fields". American Sociological Review, v.48, n.2, pp.147-60.

DRAIBE, S. M.; RIESCO, M. 2009. El Estado de bienestar social en América latina: una nueva estrategia de desarrollo. Madrid: Fundación Carolina. DURKHEIM, E. 1999. Da divisão social do trabalho. São Paulo: Martins Fontes. ELIAS, N. 1994. A sociedade dos indivíduos. Rio de Janeiro: Jorge Zahar. 2000. Os estabelecidos e os outsiders. Rio de Janeiro: Jorge Zahar.

EMIRBAYER, M. 1997. "Manifesto for a relational sociology". The American Journal of Sociology, v.103, n.2, pp.281-317.

FARIA, C. A. P. 2003. "Ideias, conhecimento e políticas públicas: um inventário sucinto das principais vertentes analíticas recentes”. Revista Brasileira de Ciências Sociais, v.8, n.51, pp.21-30.

2011. "Implementação: ainda o 'elo perdido' da análise de políticas públicas no Brasil?”. Trabalho apresentado no GT de Políticas Públicas do $35^{\circ}$ Encontro Anual da Anpocs. Caxambu.

FELD, S. L. 2002. "On the emergence of social norms". Contemporary Sociology, v.31, n.6, pp.638-40.

FIGUEIREDO, A. L. V. 2008. O caminho quilombola: interpretação constitucional e reconhecimento de direitos étnicos. Rio de Janeiro, 256 p. Tese de Doutorado. Instituto Universitário de Pesquisas do Rio de Janeiro.

FOUCAULT, M. 1979. Microfísica do poder. Rio de Janeiro: Graal. 1987. Vigiar e punir: nascimento da prisão. Rio de Janeiro: Vozes. 1996. Tecnologias del yo y otros textos afines. Barcelona: Paidós Ibérica.

FRASER, N. 2001. "Da redistribuição ao reconhecimento? Dilemas da justiça na era pós-socialista”. In: SOUZA, J. (org.). Democracia hoje: novos desafios para a teoria democrática contemporânea. Brasília: Ed. da UnB, pp.246-82. GIDDENS, A. 1989. A constituição da sociedade. São Paulo: Martins Fontes. GOFFMAN, E. 1959. The presentation of self in everyday life. Garden City, NY: Doubleday.

1961. Asylums: essays on the social situation of mental patients and other inmates. Garden City, NY: Anchor Books.

GRAMSCI, A. 2004. Cadernos do cárcere. Rio de Janeiro: Civilização Brasileira. HABERMAS, J. 1989. The structural transformation of the public sphere. Cambridge, MA: MIT Press.

HALL, P. A.; TAYLOR, R. 1996. "Political science and the three new institutionalisms". Political Studies, v.44, n.3, pp.936-957. 
1998. "The potential of historical institutionalism: a response to hay and wincott”. Political Studies, v.46, n.5, pp.958-62.

HARKER, R. et al. 1990. An introduction to the work of Pierre Bourdieu: the practice of theory. Houndmills/ Basingstoke/ Hampshire: Palgrave Macmillan.

HAY, C. 1996. Re-stating social and political change. Buckingham, Uk/ Philadelphia: Open University Press.

2002. Political analysis: a critical introduction. Houndmills/ Basingstoke/ Hampshire / New York: Palgrave.

.; WINCOTT, D. 1998. "Structure, agency and historical institutionalism”. Political Studies, v.46, n.5, pp.951-57.

HOGGETT, P. 2001. "Agency, rationality and social policy". Journal of Social Policy, v.30, n.1, pp.37-56.

HOLM, L.; SMIDT, S. 1997. "Uncovering social structures and status differences in health systems". The European Journal of Public Health, v.7, n.4, pp.373-78.

HONNETH, A. 2003. Luta por reconhecimento: a gramática moral dos conflitos sociais. São Paulo: Editora 34.

HOOK, W. et al. 1982. "Frequency of visitation in nursing homes: patterns of contact across the boundaries of total institutions". The Gerontologist, v.22, n.4, pp.424-28.

HOWLETT, M.; RAMESH, M. 1998. "Policy subsystem configurations and policy change: operationalizing the postpositivist analysis of the politics of the policy process". Policy Studies Journal, v.26, n.3, pp.466-81.

IBGE. 2008. Pesquisa nacional por amostra de domicílio (PNAD). Disponível em http:/ /www.ibge.gov.br/home/estatistica/populacao/trabalhoerendimento/pnad2009/default.shtm. Acesso em 10/07/2008.

2010. Pesquisa mensal de emprego (PME). Disponível em http:/ / www.ibge.gov.br/home/estatistica/pesquisas/pesquisa_resultados. php?indicador=1\&id_pesquisa=38. Acesso em 15/12/2010.

IMMERGUT, E. M. 1998. "The theoretical core of the new institutionalism”. Politics and Society, v.26, n.1, pp.5-34.

INGRAM, H. et al. 2007. "Social construction and policy design". In: SABATIER, P. A. (org.). Theories of the policy process. Boulder, CO: Westview Press, pp.93-126.

JESSOP, B. 1990. State theory: putting the capitalist state in its place. Cambridge: Polity.

2003. "Bringing the state back in (yet again): reviews, revisions, rejections, and redirections". Disponível em http://eprints.lancs. ac.uk/171/. Acesso em 23/02/2003. 
KINGDON, J. W. 1995. Agendas, alternatives and public policies. New York: Longman.

KORPI, W. 2000. "The power resources model”. In: CASTLES, F.; PIERSON, C. (orgs.). The welfare state: a reader. Cambridge, UK/ Malden, MA: Polity Press, pp.76-95.

LUHMANN, N. 1991. Sistemas sociales: lineamientos para una teoría general. México, DF: Alianza Editorial; Universidad Iberoamericana.

MARTINS, C. 2008. "Notas sobre o sentimento de embaraço em Erving Goffman”. Revista Brasileira de Ciências Sociais, v.23, n.68, pp.137-144.

MARX, K. 1964. El Capital: crítica de la economía política. México, DF: Fondo de Cultura Económica.

McADAM, D. 2003. "Beyond structural analysis: toward a more dynamic understanding of social movements”. In: DIANI, M.; McADAM, D. (orgs). Social movements and networks: relational approaches to collective action. Oxford/ New York: OUP, pp.281-98.

McANNULA, S. 2002. "Structure and agency". In: MARSH, D.; STOKER, G. (orgs.). Theory and methods in political science. Houndmills/ Basingstoke/ Hampshire: Palgrave Macmillan, pp.271-91

McCOOL, D. 1998. "The subsystem family of concepts: a critique and a proposal”. Political Research Quarterly, v.51, n.2, pp.551-70.

60 MELUCCI, A. 1985. "The symbolic challenge of contemporary movements”. Social Research, v.53, n.4, pp.798-816.

2001. A invenção do presente: movimentos sociais nas sociedades complexas. Petrópolis: Vozes.

MELO, M. A. 1999. "Estado, governo e políticas públicas”. In: MICELI, S. (org.). O que ler na ciência social brasileira (1970-1995). São Paulo: Sumaré; v.3, pp.59-100.

MILITÃO, M.; PINTO, C. 2008. "Governamentalidade, cultura política e a reflexividade dos riscos sociais: o caso da política portuguesa de inclusão social". Disponível em http://www.aps.pt/vicongresso/pdfs/202.pdf. Acesso em 06/10/2012.

MILLER, E. A.; BANASZAK-HOLL, J. 2005. "Cognitive and normative determinants of state policy making behavior: lessons from the sociological institutionalism”. Publius, v.35, n.2, pp.191-216.

MULLER, P.; SUREL, Y. 2002. A análise de políticas públicas. Pelotas: Educat.

OFFE, C. 1989. Capitalismo desorganizado: transformações contemporâneas do trabalho e da política. São Paulo: Brasiliense.

ORR, S. K. 2006. "Policy subsystems and regimes: organized interests and climate change policy". The Policy Studies Journal, v.34, n.2, pp.147-169. 
OSTROM, E. 2007. "Institutional rational choice: an assessment of the institutional analysis and development of framework". In: SABATIER, P. (org.). Theories of the policy process. Boulder, CO: Westview Press, pp.21-64.

OWEN-SMITH, J.; POWELL, W. W. 2008. "Networks and institutions". In: GREENWOOD, R. et al. (orgs.). The Sage handbook of organizational institutionalism. London: Sage, pp.594-621.

PETERS, G. et al. 2005. "The politics of path dependency: political conflict in historical institutionalism". The Journal of Politics, v.67, n.4, pp.1275-300.

PEILLON, M. 1999. "Bourdieu's field and the sociology of welfare". Journal of Social Policy, v.27, n.2, pp.213-29.

PIERSON, P. 1993. "Review: When effect becomes cause: policy feedback and political change". World Politics, v.45, n.4, pp.595-628.

PINKER, R. 1989. "Social work and social policy in the twentieth century: retrospect and prospect”. In: BULMER, M. et al. (orgs). The goals of social policy. London/ Boston: Unwin Hyman, pp.84-107.

POGREBINSCHI, T. 2004. "Foucault, para além do poder disciplinar e do biopoder”. Lua Nova, v.63, pp.179-201.

SABATIER, P. A. 1988. "An advocacy coalition framework of policy change and the role of policy-oriented learning therein". Policy Sciences, v.21, n. 2-3, pp.129-68.

; JENKINS-SMITH, H. C. 1993. Policy change and learning: an advocacy coalition approach. Boulder, CO: Westview Press.

; WEIBLE, C. M. 2007. "The advocacy coalition framework: innovation and clarifications”. In: SABATIER, P. A. (org.). Theories of the policy process. Boulder, CO: Westview Press, pp.189-220.

SCHERER-WARREN, I. 1993. Redes de movimentos sociais. São Paulo/ Rio de Janeiro: Loyola; Centro João XXIII.

SCOTT, W. R. 1992. Organizations: rational, natural, and open systems. Englewood Cliffs, NJ: Prentice Hall.

SCHARPF, F. W. 1997. Games real actors play: actor-centered institutionalism in policy research. Boulder, CO: Westview Press.

SIMON, H.; MARCH, J. 1967. Teoria das organizações. Rio de Janeiro: FGV; USAID.

SOUZA, C. 2006. "Políticas públicas: uma revisão da literatura". Sociologias, ano 8, n.16, pp.20-45.

TAYLOR, C. 1994. Multiculturalismo: examinando a política de reconhecimento. Lisboa: ed. do Instituto Piaget.

TOURAINE, A. 1981. The voice and the eye: an analysis of social movements. Cambridge, UK/ New York: CUP. 
TRUE, J. L et al. 2007. "Punctuated-equilibrium theory: explaining stability and change in public policy making". In: SABATIER, P. A. (org.). Theories of the policy process. Boulder, CO: Westview Press, pp.155-87.

WAIZBORT, L. (org.) 1999. Dossiê Norbet Elias. São Paulo: Edusp.

WEBER, M. 1977. Economía y sociedad. México, DF: Fondo de Cultura Económica.

WEINSTEIN, R. 1982. "Goffman's asylums and the social situation of mental patients". Journal of Orthomolecular Psychiatry, v.11, pp.267-74.

WILLIAMS, F. 1999. "Good-enough principles for welfare". Journal of Social Policy, v.28, n.4, pp.667-87.

WILSON, J. 1993. "The moral sense: presidential address, American political science association". The American Political Science Review, v.87, n.1, pp.1-11.

WORSHAM, J. 1998. "Wavering equilibriums: subsystem dynamics and agenda control". American Politics Quarterly, v.26, n.4, pp.485-512. 


\section{A CONTRIBUIÇÃO DA SOCIOLOGIA PARA A ANÁLISE DE POLÍTICAS PÚBLICAS}

SORAYA VARGAS CORTES LUCIANA LEITE LIMA

238 Resumo: $\mathrm{O}$ objetivo do artigo é examinar possíveis contribuições da sociologia para a análise de políticas públicas. Argumenta-se que os recursos teóricos que a sociologia oferece ao enfocar os grupos sociais, as normas sociais e as interações entre estrutura social e instituições políticas, são importantes ferramentas na construção de modelos analíticos dirigidos à compreensão dos processos de formulação e implementação de políticas públicas.

Palavras-chave: Sociologia; Políticas Públicas; Análise de Políticas; Atores Societais; Imperativos Cognitivos; Imperativos Normativos; Instituições.

\section{THE CONTRIBUTION OF SOCIOLOGY TO POLICY ANALYSIS}

Abstract: This article aims to examine possible contributions of sociology to the policy analysis. It argues that theoretical resources offered by sociology - that concentrates itself on social groups, on social norms and on the relationship between social structure and political institutions - are important tools to build up analytical models aiming to understand public policies processes. 
Keywords: Sociology; Public Policies; Policy Analysis; Societal Actors; Cognitive Imperatives; Normative Imperatives; Institutions.

Recebido: 15/03/2012 Aprovado: 29/08/2012 